\title{
DRD3 Ser9Gly Polymorphism and Its Influence on Risperidone Response in Autistic Children
}

\author{
Negar Firouzabadi ${ }^{1,2 *}$, Anna Nazariat ${ }^{3}$, Kamiar Zomorrodian ${ }^{4}$ \\ ${ }^{1}$ Pharmaceutical Sciences Research Center, Shiraz University of Medical Sciences, Shiraz, Iran. ${ }^{2}$ Department of \\ Pharmacology \& Toxicology, School of Pharmacy, Shiraz University of Medical Sciences, Shiraz, Iran. ${ }^{3}$ Department of \\ Pharmacology, School of Pharmacy, Shiraz University of Medical Sciences, International Branch, Shiraz, Iran. ${ }^{4}$ Department \\ of Medical Parasitology and Mycology, School of Medicine, Shiraz University of Medical Sciences, Shiraz, Iran.
}

Received, November 9, 2017; Revised, December 4; Accepted, December 8, 2017; Published, December 17, 2017.

\begin{abstract}
PURPOSE: Autism, a neuropsychiatric illness, is a complex ailment of mainly indefinite cause. Although precise pathophysiological mechanism is unclear but the role of genetics is undeniable therefore pharmacogenetics may assist to a better management of symptoms. Risperidone is widely used in autism. Considering the significance of dopaminergic system in psychological and neurological diseases and its association with autism, the hypothesis that genetic variant of dopamine receptor (DRD3), Ser9Gly (rs6280), may influence treatment of autism may be assumed. METHOD: In the present study, 56 autistic Persian children within the age range of 2.5 to 14 years were included. Diagnosis of autism was based on DSM-V criteria and the severity degree was measured by $\mathrm{ABC}-\mathrm{C}$ checklists at base line and after 8 weeks of treatment with risperidone. Based on their scores patients were categorized as responsive and non-responsive groups. DRD3 Ser9Gly (rs6280) was determined by PCR-RFLP. RESULTS: Carriers of Gly allele as well as carriers of Gly/Gly and Ser/Gly genotypes showed significantly better response to risperidone compared with carriers of Ser allele and Ser/Ser genotype $\quad(\mathrm{P}=0.027 ; \quad \mathrm{OR}=4.18 ; \quad 95 \% \mathrm{CI}=1.16-15.03 \quad$ and $\mathrm{P}=0.014 ; \quad \mathrm{OR}=6.825 ; \quad 95 \% \mathrm{CI}=1.36-34.13)$. CONCLUSION: Our results advocate the possible influence of genetic variation of DRD3 in clinical response to antipsychotics like risperidone in autistic individuals.

This article is open to POST-PUBLICATION REVIEW. Registered readers (see "For Readers") may comment by clicking on ABSTRACT on the issue's contents page.
\end{abstract}

\section{INTRODUCTION}

Autism, being a multifactorial illness, comprise a group of mental disorders which are characterized with the abnormality in social interactions, communication skills and repetitive behaviors (1).

The prevalence of the disease in the United States of America is swiftly increasing. Based on a report in 2014, the prevalence of autism is $2.24 \%$ which exhibits a significant rise in the recent years (2). In developing countries, reliable estimates of the frequency of autism is lacking and the epidemiology of the disease is not yet well defined. According to a study conducted on the students who entered the preliminary school in 2008 in Iran, the prevalence of autism was 19 in every 1000 individuals (3).

The major etiology of this illness is not fully understood to date but it has long been assumed that genetic factors contribute significantly to its pathophysiology (4-6). Studies on identical twins, highlight this issue the most where 60 percent probability of autism for monozygotic twins was observed. In the case of dizygotic twins, prevalence of such disorders is about 10 percent. In addition, hereditary state of the disorder was estimated to be more than 90 percent (7). These reports highlight the role of genetics in autism.

Among many neurotransmitters, the role of dopamine and its receptors in autism have been extensively studied (8-10). Dopaminergic pathway and particularly the dopamine receptors have been sturdily implicated in autism (11). Dopamine and its receptors (D1-D5) are critically involved in mental functions such as attention, memory and the ability of problem solving.

\footnotetext{
Corresponding Author: Negar Firouzabadi PhD, Department of Pharmacology \& Toxicology, School of Pharmacy, Shiraz University of Medical Sciences, Shiraz, Iran; E-mail: Firouzabadi@sums.ac.ir, nfirouzabadi@yahoo.com
} 
The D3 and D4 receptors as the members of D2 receptor family, have substantial roles in emotional, cognitive, and motor functions (12) which are all affected in autism. The function of dopaminergic system in the frontal and pre frontal cortex is reported to be affected in autistic patients. Moreover, the two areas which are rich in dopamine and dopamine receptors: striatum and the mesolimbic cortex, are involved in the autism pathophysiology. This further suggests the role of this neurotransmitter in autism $(13,14)$.

Dopamine receptor antagonists are effective in reducing the symptoms of autism like aggression, self-injury and mandatory behaviors. Risperidone, initially classified as an antipsychotic drug, shows high affinity towards D3 receptors (DRD3) (15). Among the autistic patients receiving risperidone, $67 \%$ benefit from long-term use of the drug but the remaining 33\% do not (16). As known, patients do not respond similarly to the same doses of the same drug for a variety of reasons. Genetic factors are likely to be the key determinant and account for $20 \%$ to $95 \%$ of the variability in drug effects (17). Not much evidence exists regarding the genetic factors underling these inter individual differences in treatment response in autism (18); however, genetics of dopaminergic pathway seem to be a reasonable candidate for differential risperidone response.

Several studies regarding the association of DRD3 with autism have been conducted $(8,19,20)$. Considering the complex nature of autism and the inter-individual variations in response to different antipsychotic medications, we hypothesized that therapeutic outcomes might be affected by genetics of DRD3 to some extent. Hence we studied, for the first time, the association between DRD3 Ser/Gly polymorphism (rs6280) and risperidone treatment outcome in a population of Iranian autistic patients.

\section{METHODS \& MATERIALS}

\section{Study Population}

The study was approved by the local committee of ethics of medical experiments on human subjects of Shiraz University of Medical Sciences and was carried out in accordance with Uniform Requirements for manuscripts submitted to biomedical journals and The Code of Ethics of the World Medical Association (Declaration of Helsinki). Informed written consent (approved by The Institutional Ethical Committee) was obtained from parents/legal representatives of all individual participants included in the study.

Fifty-six autistic outpatient participants referred to Imam Reza Clinic of Shiraz from 2013 to 2015 were enrolled in this study. Diagnosis of autism was based on DSM-V criteria (21) and confirmed by a child psychiatrist. They were regularly followed up for at least 1 year by the specialist. The severity of autism was assessed using Autism Behavior Checklist (ABC-C) (22). The checklist consists of 57 items and can be used for assessment of drug efficacy. It describes a series of typical autistic behaviors. The scale comprises five main areas of sensory, relating, stereotypes and object use, language, and self-help and social communication. The total score is obtained by adding the scores for the different areas. The 57 items are as follows: 9 items in sensory area, 12 in relating, 12 in stereotypes and object use, 13 in language, 11 in selfhelp and social communication (23).

Medication was given at home and by their parents. The dose of risperidone was titrated up to 2 $\mathrm{mg} /$ day $(0.5 \mathrm{mg}$ starting dosage with $0.5 \mathrm{mg}$ increase in weekly dosage for the first 3 weeks) for children between 10 and $40 \mathrm{~kg}$ and $3 \mathrm{mg} /$ day for children weighting above $40 \mathrm{~kg}$.

It should be noted that these participants had not taken any other neuroleptics or any psychotropic medicines within the past six months and children with any psychotic disorders, schizophrenia and severe mental retardation were excluded from our study. Before the treatment and 8 weeks after initiation of treatment, the severity of autism was assessed using $\mathrm{ABC}-\mathrm{C}$ questionnaire.

Patients were further divided at week 8 into two groups of treatment-responsive and non-responsive based on at least $50 \%$ reduction in the $\mathrm{ABC}-\mathrm{C}$ scores. The extent of severity of autism symptoms based on the ABC-C scores at 8 weeks were evaluated for all participants with no dropouts. Response was defined as a $50 \%$ or greater decrease from baseline $\mathrm{ABC}-\mathrm{C}$ score (24). Blood samples for DNA extraction and genotyping were collected prior to treatment.

\section{Genotyping}

CINNA PURE ${ }^{\circledR}$ DNA kit was used to extract patients' DNA from their peripheral white blood cells. The polymorphism of DRD3 gene (rs6280), which results in a serine to glycine substitution at position 9 in the $\mathrm{N}$-terminal part of the extracellular domain of the dopamine D3 receptor (25), was assayed based on a standard PCR protocol (26). 
Amplification of the polymorphism was conducted using the following primers:

\section{5'-GCTCTATCTCCAACTCTCACA-3' 5'-AAGTCTACTCACCTCCAGGTA-3'.}

The PCR products were then digested overnight at $37^{0 \mathrm{C}}$ with $\mathrm{MscI}$ restriction enzyme (New England Biolabs $^{\circledR}$ ).

An Eppendorf gradient Master cycler (Hamburg, Germany) PCR machine was used as the thermal cycler. In order to separate digested fragments electrophoresis on $3 \%$ agarose (Invitrogen ${ }^{\circledR}$ Ultra Pure) gel was used. The gels were then stained by ethidium bromide and visualized in a UV trans illuminator. All samples were genotyped at least twice and the results were reconfirmed.

\section{STATISTICS}

The data were analyzed with SPSS $₫ 22.0$ software for windows ${ }^{\circledR}$ (SPSS Inc., Chicago, Illinois). The frequency of alleles and genotypes are presented in percentage (\%). Continuous variables are stated as Mean \pm SD. Distribution of all continuous variables was tested for normal distribution with the Kolmogorov-Smirnov test. Chi-square $\left(\chi^{2}\right)$ test was used to estimate Hardy-Weinberg equilibrium (HWE) for the distributions of genotypes. For comparing the means, ANOVA test and Student's ttest were performed. The association between each polymorphism and response to treatment was evaluated by $\chi^{2}$ test. Odds ratio (OR) and $95 \%$ confidence intervals (CI) were calculated; $p<0.05$ was considered statistically significant.

\section{RESULTS}

Fifty-six autistic children (40 males, 16 females) within the age range of 2.5 to 14 years (mean \pm S.D = $6.8 \pm 1.3)$ were genotyped for DRD3 Ser9Gly (rs6280). Genotypes of the studied polymorphism were in Hardy-Weinberg Equilibrium $\left(\chi^{2}: 2.45\right.$, df:1, $\mathrm{P}>0.05$ ). Demographic characteristics of the patients are shown in Table 1 . Only one child was $<10 \mathrm{~kg}$ and received $0.5 \mathrm{mg}$ starting dosage with $0.5 \mathrm{mg}$ increase in weekly dosage for the first 3 weeks. Among the study groups, 41 patients $(73 \%)$ were responsive to risperidone and 15 were non-responsive to treatment (27\%). Table 2 demonstrates the two-by-two comparison of the $\mathrm{ABC}-\mathrm{C}$ scores of the risperidone responsive and non-responsive autistic patients $(\mathrm{P}$ values $<0.001)$. Genotype and allele frequencies of DRD3 Ser9Gly of both responsive and nonresponsive groups are demonstrated in Table 3. Individuals with either Ser/Gly or Gly/Gly genotypes responded significantly better to risperidone than patients carrying Ser/Ser genotype $(\mathrm{P}=0.014 ; \quad \mathrm{OR}=6.8 ; 95 \% \mathrm{CI}=1.36-34.13)$. On the other hand, Gly allele was also significantly associated with better response to risperidone than the Ser allele $(\mathrm{P}=0.027$; $\mathrm{OR}=4.18 ; 95 \% \mathrm{CI}=1.16$ 15.03). Table 4 demonstrates ABC-C scores at baseline and week 8 in different DRD3 genotypes based on response to risperidone treatment.

Table 1. Demographic characteristics of the enrolled patients

\begin{tabular}{ll}
\hline Variables & Autistic patients $(\mathrm{n}=56)$ \\
\hline Male/female (\%) & $40 / 16(71.4 / 28.6)$ \\
Age, mean $\pm \mathrm{SD}($ years) & $6.9 \pm 1.1$ \\
Body mass index (kg/m2 ) & $16.2 \pm 3.1$ \\
History of psychiatric and/or neurological illnesses & First degree relatives, $6(10.7 \%) ;$ Others, $18(32.1 \%) ;$ \\
& None, 32 (57.1\%) \\
\hline
\end{tabular}

Table2. Two-by-two comparison of the ABC-C scores of the autistic patients

\begin{tabular}{cccl}
\hline \multicolumn{1}{c}{ Scale } & & (Mean \pm SD) & $p$ \\
\hline ABC-C & $\mathrm{ABC} \mathrm{C}_{0}$ & $\mathrm{ABC}-\mathrm{C}_{1}$ & $<0.0001$ \\
& $48.2 \pm 23.4$ & $30.3 \pm 24.1$ & \\
\hline
\end{tabular}

$\mathrm{ABC}^{-\mathrm{C}_{0}}$ : $\mathrm{ABC}-\mathrm{C}$ score at baseline; $\mathrm{ABC}-\mathrm{C}_{1}$ : $\mathrm{ABC}-\mathrm{C}$ score at week 8 
Table3. Genotype and allele frequencies of Ser9gly drd3 variant in autistic patients receiving risperidone

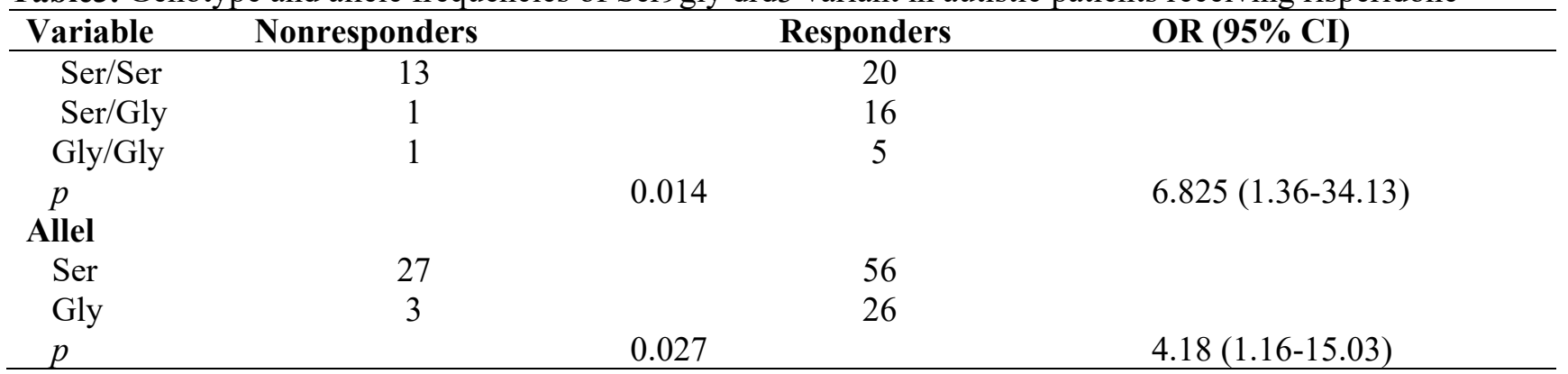

Table 4. ABC-C scores at baseline and week 8 in different DRD3 genotypes based on response to treatment

\begin{tabular}{lcccccc}
\hline & \multicolumn{2}{c}{ Ser/Ser } & \multicolumn{2}{c}{ Ser/Gly } & \multicolumn{2}{c}{ Gly/Gly } \\
& Responders & Nonresponders & Responders & Nonresponders & Responders & Nonresponders \\
\hline ABC-C $_{0}$ & $50.8 \pm 25.6$ & $53.3 \pm 31.8$ & $36.9 \pm 16.5$ & 44 & $57 \pm 24.3$ & 88 \\
ABC-C ${ }_{1}$ & $24.7 \pm 12.5$ & $51.5 \pm 3.5$ & $17.9 \pm 8.1$ & 42 & $26.0 \pm 13.6$ & 86 \\
\hline ABC-C 0 : ABC-C score at baseline; ABC-C1: ABC-C score after 8 weeks of treatment & \\
\hline
\end{tabular}

\section{DISCUSSION}

To the best of our knowledge, this study is the first to investigate the relationship between DRD3 genetic variants and response to risperidone in Iranian autistic children. Here we found that autistic patients that carry the Gly allele of DRD3 Ser9gly (rs6280) respond approximately four times better to risperidone than patients with the Ser allele. Likewise, carriers of Gly/Gly and Ser/Gly genotypes responded six times more to risperidone comparing with Ser/Ser carriers.

Diagnosis rate of autism is globally increasing; however, management of symptoms is fairly satisfactory. While many studies highlight the influence of genetics in pathophysiology of autism, its part as therapeutic determinant remains ambiguous. DRD3 receptor, a G-protein-coupled receptor (GPCRs), plays a prominent role in the neurotransmission regulation by influencing spontaneous secretion of other neurotransmitters (27). The super family of GPCRs contribute in many psychiatric and neuropsychiatric illnesses $(28,29)$. Among the GPCRs, the eminent role of DRD3 in etiology and therapeutic response of many of these disorders has been frequently reported $(8,30-32)$. However, except a few studies $(8,33)$ not much has been conveyed regarding autism.

Imaging and biomedical research have supported the involvement of dopaminergic system in the pathophysiology of autism. Reviewing positron emission tomography scans in a number of autistic children in one study, revealed low levels of dopaminergic activity in medial prefrontal cortex (34) which is evocative of the role of dopamine in autism. Dopaminergic system is distributed further in the orbitofrontal cortex of autistic individuals which in turn suggests the over functioning of this system in this patient population (35).

As a means of targeted treatment and personalized medicine, pharmacogenetics has currently drawn a lot of attention in many neurologic and psychiatric diseases (36-40). Although many studies have focused on the contribution of genetic factors in autism $(41,42)$, their role as therapeutic elements stays illusive. Considering the significance of dopamine system in behavior and perception and its dysregulation in mental and neurological diseases such as autism, the association between genetic polymorphisms of this system and autism pathophysiology and therapeutics is undeniable (43).

Risperidone as an atypical antipsychotic is approved for management of symptoms in autism. Although dopamine receptor polymorphisms have been frequently studied in schizophrenia for decades, their part in behavioral disorders such as autism is still under investigation. DRD3, as an important site of action for risperidone, is vastly expressed in the 
caudate nucleus which is significantly enlarged in autistic patients (44). Thus, DRD3 receptor polymorphisms may influence response to risperidone. DRD3 Ser9gly variant (rs6280) located in the first exon of the DRD3 gene leads to a substitution of serine to glycine in the receptor's Nterminal extracellular domain (25) and has been recently focused on in pharmacogenetics studies, but the results were not conclusive (45-47). Among the variants of DRD3, Ser9Gly (rs6280) is the only polymorphism that affects protein structure (25).

Some reports has previously suggested this variant to be a predictor for clinical improvement with risperidone therapy $(33,48)$ and also a parameter associated with risperidone side effects (49). On the other side, some studies suggest no significant contribution of this variant to risperidone treatment $(30,50)$. For example, in a report by Chen $\mathrm{S}-\mathrm{F}$ et al., this variant was not associated with aripiprazole treatment in schizophrenic patients (51). However, in another report by Scharfetter $\mathrm{J}$ et al., schizophrenic patients carrying the Gly allele responded significantly better to clozapine (52). Regarding treatment with antipsychotics a study is suggestive of a significant association between DRD3 Ser9Gly polymorphism (rs6280) and treatment response in a group of schizophrenic patients (53) while another study in a population of schizophrenic patients proposes that carriers of Ser allele or Ser/Ser genotype responded worse than non-carriers of this variant to atypical antipsychotics (54).

It has been suggested that the Gly allele of this polymorphism could influence intracellular signaling pathways, although the exact molecular basis and the clinical relevance of this effect remain vague (55). The higher binding affinity for dopamine in cells expressing the Gly allele (56) may explain the results of our study. While, the in-vivo functional significance of the polymorphic Ser9Gly site is not clear, the in-vitro DRD3 receptor-binding analysis has suggested that both Gly/Gly and Ser/Gly genotypes exhibits significantly higher binding affinities for GR99841, the selective D3 ligand, compared with Ser/Ser genotype (56). These studies suggest for either analyzing the Gly/Gly variant against all the other genotypes or for grouping the Gly/Gly and Ser/Gly variants against Ser/Ser, the wild-type genotype. However, extrapolating to an in vivo model must be with caution, since an in vitro system does not necessarily reflect an in vivo receptor status (57).
One advantage of our study was enlisting merely the newly diagnosed autistic patients who were receiving risperidone for the first time and meanwhile no other concomitant drugs were used. This may minimize the confounding effects of other drugs in observing a better response rate to risperidone in carriers of Gly allele in DRD3 gene. One limitation of the study was that the plasma concentration of risperidone was not measured mainly because of difficulties of frequent blood sampling in autistic children. This could be the subject of a future study to determine the association between risperidone plasma concentrations and DRD3 genetic variants.

In summary we found that autistic patients with Gly allele or Gly/Gly, Ser/Gly genotypes responded significantly better to risperidone. However, other polymorphisms located in the introns as well as variants in the regulatory regions at the $5^{\prime}$ or the $3^{\prime}$ end of the gene, could cause the variability related to different treatment responses, mainly by alterations in the mRNA stability. Given the complexity of the genetics of autism, the present study may provide some information regarding the effect of the studied polymorphism and response to risperidone in this illness and further contribute to personalize medication for autistic patients, provided our findings are replicated. Thus new studies are needed to address the potential pharmacogenetic implications of the DRD3 Ser/Gly variant.

\section{ACKNOWLEDGEMENT}

The authors would like to thank Pharmaceutical Sciences Research Center, Shiraz University of Medical Sciences, Shiraz, Iran for its financial support. We sincerely acknowledge Dr. Ali Alavi Shoushtari for his kind contribution towards patient selection.

\section{REFERENCES}

1. Nietzel M, Wakefield J. American Psychiatric Association Diagnostic and Statistical Manual of Mental Disorders. CONTEMPORARY PSYCHOLOGY. 1996;41:642-51.

2. Zablotsky B, Black LI, Maenner MJ, Schieve LA, Blumberg SJ. Estimated prevalence of autism and other developmental disabilities following questionnaire changes in the 2014 National Health Interview Survey. 2015; 87:1-20 
3. Mohammadi MR, Salmanian M, Akhondzadeh S. Autism spectrum disorders in Iran. Iranian Journal of Child Neurology. 2011;5(4):1-9.

4. Cook Jr E. Genetics of autism. Child and Adolescent Psychiatric Clinics of North America. 2001;10(2):333-50.

5. Abrahams BS, Geschwind DH. Genetics of autism. Vogel and Motulsky's Human Genetics: Springer; 2010;699-714.

6. De Rubeis S, Buxbaum JD. Recent Advances in the Genetics of Autism Spectrum Disorder. Current neurology and neuroscience reports. 2015;15(6):1-9.

7. Ho A, Todd RD, Constantino JN. Brief report: autistic traits in twins vs. non-twins - a preliminary study. Journal of autism and developmental disorders. 2005;35(1):129-33.

8. Staal WG, de Krom M, de Jonge MV. Brief report: the dopamine-3-receptor gene (DRD3) is associated with specific repetitive behavior in autism spectrum disorder (ASD). Journal of autism and developmental disorders. 2012;42(5):885-8.

9. Emanuele E, Boso M, Cassola F, Broglia D, Bonoldi I, Mancini L, et al. Increased dopamine DRD4 receptor mRNA expression in lymphocytes of musicians and autistic individuals: bridging the music-autism connection. Neuro Endocrinol Lett. 2010;31(1):122-5.

10. Hettinger JA, Liu X, Hudson ML, Lee A, Cohen IL, Michaelis RC, et al. DRD2 and PPP1R1B (DARPP32) polymorphisms independently confer increased risk for autism spectrum disorders and additively predict affected status in male-only affected sib-pair families. Behavioral and brain functions. 2012;8(1):19.

11. Nguyen M, Roth A, Kyzar EJ, Poudel MK, Wong K, Stewart AM, et al. Decoding the contribution of dopaminergic genes and pathways to autism spectrum disorder (ASD). Neurochemistry International. 2014;66:15-26.

12. Suzuki M, Hurd YL, Sokoloff P, Schwartz J-C, Sedvall G. D 3 dopamine receptor mRNA is widely expressed in the human brain. Brain research. 1998;779(1):58-74.

13. Damasio AR, Maurer RG. A neurological model for childhood autism. Archives of neurology. 1978;35(12):777-86.

14. Maurer RG, Damasio AR. Childhood autism from the point of view of behavioral neurology. Journal of autism and developmental disorders. 1982;12(2):195205.

15. Schwartz J-C, Diaz J, Pilon C, Sokoloff P. Possible implications of the dopamine D 3 receptor in schizophrenia and in antipsychotic drug actions. Brain Research Reviews. 2000;31(2):277-87.

16. Dove D, Warren Z, McPheeters ML, Taylor JL, Sathe NA, Veenstra-VanderWeele J. Medications for adolescents and young adults with autism spectrum disorders: a systematic review. Pediatrics. 2012;130(4):717-26.

17. Hawcutt DB, Thompson B, Smyth RL, Pirmohamed M. Paediatric pharmacogenomics: an overview. Archives of disease in childhood. 2013;98(3):232-7.

18. Correia C, Vicente AM. Pharmacogenetics of risperidone response and induced side effects. 2007; 4

19. de Krom M, Staal WG, Ophoff RA, Hendriks J, Buitelaar J, Franke B, et al. A common variant in DRD3 receptor is associated with autism spectrum disorder. Biological psychiatry. 2009;65(7):625-30.

20. Staal WG, Langen M, Van Dijk S, Mensen VT, Durston S. DRD3 gene and striatum in autism spectrum disorder. The British Journal of Psychiatry. 2015;206(5):431-2.

21. Association AP. Diagnostic and statistical manualtext revision (DSM-IV-TRim, 2000): American Psychiatric Association; 2000.

22. Krug D, Arick J, Almond P. ABC-Autism behaviour checklist. Portland, OR: ASIEP Education Co. 1978.

23. Rellini E, Tortolani D, Trillo S, Carbone S, Montecchi F. Childhood Autism Rating Scale (CARS) and Autism Behavior Checklist (ABC) correspondence and conflicts with DSM-IV criteria in diagnosis of autism. Journal of autism and developmental disorders. 2004;34(6):703-8.

24. Shea S, Turgay A, Carroll A, Schulz M, Orlik H, Smith I, et al. Risperidone in the treatment of disruptive behavioral symptoms in children with autistic and other pervasive developmental disorders. Pediatrics. 2004;114(5):e634-e41.

25. Lannfelt L, Sokoloff P, Martres M-P, Pilon C, Giros $\mathrm{B}$, Jönsson E, et al. Amino acid substitution in the dopamine D3 receptor as a useful polymorphism for investigating psychiatric disorders. Psychiatric Genetics. 1992;2(4):249-56.

26. Ebstein RP, Macciardi F, Heresco-Levi U, Serretti A, Blaine D, Verga M, et al. Evidence for an association between the dopamine D3 receptor gene DRD3 and schizophrenia. Human heredity. 1997;47(1):6-16.

27. Kuzhikandathil EV, Oxford GS. Dominant-negative mutants identify a role for GIRK channels in D3 dopamine receptor-mediated regulation of spontaneous secretory activity. The Journal of general physiology. 2000;115(6):697-706.

28. Catapano LA, Manji HK. G protein-coupled receptors in major psychiatric disorders. Biochimica et Biophysica Acta (BBA)-Biomembranes. 2007;1768(4):976-93.

29. Lau CG, Zukin RS. NMDA receptor trafficking in synaptic plasticity and neuropsychiatric disorders. Nature reviews neuroscience. 2007;8(6):413-26.

30. Kim B, Choi EY, Kim CY, Song K, Joo YH. Could HTR2A T102C and DRD3 Ser9Gly predict clinical improvement in patients with acutely exacerbated 
schizophrenia? Results from treatment responses to risperidone in a naturalistic setting. Human Psychopharmacology: Clinical and Experimental. 2008;23(1):61-7.

31. Liou Y-J, Liao D-L, Chen J-Y, Wang Y-C, Lin C-C, Bai Y-M, et al. Association analysis of the dopamine D3 receptor gene ser9gly and brain-derived neurotrophic factor gene val66met polymorphisms with antipsychotic-induced persistent tardive dyskinesia and clinical expression in Chinese schizophrenic patients. Neuromolecular medicine. 2004;5(3):243-51.

32. Paus S, Gadow F, Knapp M, Klein C, Klockgether T, Wüllner U. Motor complications in patients form the German Competence Network on Parkinson's disease and the DRD3 Ser9Gly polymorphism. Movement Disorders. 2009;24(7):1080-4.

33. Correia C, Almeida J, Santos P, Sequeira A, Marques $\mathrm{C}$, Miguel T, et al. Pharmacogenetics of risperidone therapy in autism: association analysis of eight candidate genes with drug efficacy and adverse drug reactions. The pharmacogenomics journal. 2010;10(5):418-30.

34. Ernst M, Zametkin A, Matochik J, Pascualvaca D, Cohen R. Low medial prefrontal dopaminergic activity in autistic children. The Lancet. 1997;350(9078):638.

35. Nakamura K, Sekine Y, Ouchi Y, et al. Brain serotonin and dopamine transporter bindings in adults with high-functioning autism. Archives of general psychiatry. 2010;67(1):59-68.

36. Firouzabadi N, Raeesi R, Zomorrodian K, Bahramali E, Yavarian I. Beta Adrenoceptor Polymorphism and Clinical Response to Sertraline in Major Depressive Patients. Journal of Pharmacy \& Pharmaceutical Sciences. 2017;20:1-7.

37. Bahramali E, Firouzabadi N, Yavarian I, Shayesteh MRH, Erfani N, Shoushtari AA, et al. Influence of ACE gene on differential response to sertraline versus fluoxetine in patients with major depression: a randomized controlled trial. European journal of clinical pharmacology. 2016;72(9):1059-64.

38. Baghai TC, Schule C, Zill P, Deiml T, Eser D, Zwanzger $\mathrm{P}$, et al. The angiotensin I converting enzyme insertion/deletion polymorphism influences therapeutic outcome in major depressed women, but not in men. Neuroscience letters. 2004;363(1):38-42.

39. Lozupone M, Panza F, Stella E, La Montagna M, Bisceglia P, Miscio G, et al. Pharmacogenetics of neurological and psychiatric diseases at older age: has the time come? Expert opinion on drug metabolism \& toxicology. 2017;13(3):259-77.

40. Glauser TA, Holland K, O'Brien VP, Keddache M, Martin LJ, Clark PO, et al. Pharmacogenetics of antiepileptic drug efficacy in childhood absence epilepsy. Annals of neurology. 2017;81(3):444-53.
41. Chen JA, Peñagarikano O, Belgard TG, Swarup V, Geschwind DH. The emerging picture of autism spectrum disorder: genetics and pathology. Annual Review of Pathology: Mechanisms of Disease. 2015;10:111-44.

42. Schaefer GB, Mendelsohn NJ, Practice P, Committee G. Clinical genetics evaluation in identifying the etiology of autism spectrum disorders: 2013 guideline revisions. Genetics in Medicine. 2013;15(5):399-407.

43. Reichenberg A, Gross R, Weiser M, Bresnahan M, Silverman J, Harlap S, et al. Advancing paternal age and autism. Archives of general psychiatry. 2006;63(9):1026-32.

44. Langen M, Schnack HG, Nederveen H, Bos D, Lahuis BE, de Jonge MV, et al. Changes in the developmental trajectories of striatum in autism. Biological psychiatry. 2009;66(4):327-33.

45. Yang B, Niu W, Chen S, Xu F, Li X, Wu X, et al. Association study of dopamine receptor genes polymorphisms with the risk of schizophrenia in the Han Chinese population. Psychiatry research. 2016;245:361-4.

46. Montag C, Hall J, Plieger T, Felten A, Markett S, Melchers M, et al. The DRD3 Ser9Gly polymorphism, Machiavellianism, and its link to schizotypal personality. Journal of Neuroscience, Psychology, and Economics. 2015;8(1):48.

47. Spurlock G, Williams J, McGuffin P, Aschauer H, Lenzinger E, Fuchs K, et al. European Multicentre Association Study of Schizophrenia: a study of the DRD2 Ser311Cys and DRD3 Ser9Gly polymorphisms. American Journal of Medical Genetics Part A. 1998;81(1):24-8.

48. Lane H-Y, Hsu S-K, Liu Y-C, Chang Y-C, Huang CH, Chang W-H. Dopamine D3 receptor Ser9Gly polymorphism and risperidone response. Journal of clinical psychopharmacology. 2005;25(1):6-11.

49. Gassó P, Mas S, Bernardo M, Alvarez S, Parellada E, Lafuente A. A common variant in DRD3 gene is associated with risperidone-induced extrapyramidal symptoms. The pharmacogenomics journal. 2009;9(6):404-10.

50. Xuan J, Zhao X, He G, Yu L, Wang L, Tang W, et al. Effects of the dopamine D3 receptor (DRD3) gene polymorphisms on risperidone response: a pharmacogenetic study. Neuropsychopharmacology. 2008;33(2):305-11.

51. Chen S-F, Shen Y-C, Chen C-H. Effects of the DRD3 Ser9Gly polymorphism on aripiprazole efficacy in schizophrenic patients as modified by clinical factors. Progress in Neuro-Psychopharmacology and Biological Psychiatry. 2009;33(3):470-4.

52. Scharfetter J, Chaudhry HR, Hornik K, Fuchs K, Sieghart W, Kasper S, et al. Dopamine D3 receptor gene polymorphism and response to clozapine in schizophrenic Pakistani patients. European Neuropsychopharmacology. 1999;10(1):17-20. 
53. Reynolds GP, Yao Z, Zhang X, Sun J, Zhang Z. Pharmacogenetics of treatment in first-episode schizophrenia: D3 and 5-HT2C receptor polymorphisms separately associate with positive and negative symptom response. European Neuropsychopharmacology. 2005;15(2):143-51.

54. Szekeres G, Kéri S, Juhász A, Rimanóczy Á, Szendi I, Czimmer C, et al. Role of dopamine D3 receptor (DRD3) and dopamine transporter (DAT) polymorphism in cognitive dysfunctions and therapeutic response to atypical antipsychotics in patients with schizophrenia. American Journal of Medical Genetics Part B: Neuropsychiatric Genetics. 2004;124(1):1-5.

55. Hellstrand M, Danielsen E, Steen V, Ekman A, Eriksson E, Nilsson C. The ser9gly SNP in the dopamine D3 receptor causes a shift from cAMP related to PGE2 related signal transduction mechanisms in transfected CHO cells. Journal of medical genetics. 2004;41(11):867-71.

56. Lundstrom K, Turpin MP. Proposed schizophreniarelated gene polymorphism: expression of the Ser9Gly mutant human dopamine D 3 receptor with the Semliki Forest virus system. Biochemical and biophysical research communications. 1996;225(3):1068-72.

57. Lerer B, Segman RH, Fangerau H, Daly AK, Basile VS, Cavallaro R, et al. Pharmacogenetics of tardive dyskinesia: combined analysis of 780 patients supports association with dopamine $\mathrm{D} 3$ receptor gene Ser9Gly polymorphism. Neuropsychopharmacology. 2002;27(1):105-19. 